\title{
Titanium dioxide in dental enamel as a trace element and its variation with bleaching
}

\author{
Tatiana Vargas-Koudriavtsev ${ }^{1}$, Randall Durán-Sedó ${ }^{2}$, Óscar-Andrey Herrera-Sancho ${ }^{3}$
}

${ }^{1}$ Dental Faculty, University of Costa Rica. Postgraduate Program in Prosthodontics, University of Costa Rica

${ }^{2}$ Dental Faculty, University of Costa Rica. Graduate program dental student

${ }^{3}$ School of Physics, University of Costa Rica. Materials Research Science and Engineering Center, University of Costa Rica. Institute for Quantum Optics and Quantum Information, Austrian Academy of Sciences, Innsbruck, Austria

Correspondence:

San Pedro, Montes de Oca

Ciudad Universitaria Rodrigo Facio

Facultad de Odontología

San José, Costa Rica

Tatiana.vargas_k@ucr.ac.cr

\begin{abstract}
Vargas-Koudriavtsev T, Durán-Sedó R, Herrera-Sancho OA. Titanium dioxide in dental enamel as a trace element and its variation with bleaching. J Clin Exp Dent. 2018;10(6):e537-41.

http://www.medicinaoral.com/odo/volumenes/v10i6/jcedv10i6p537.pdf
\end{abstract}

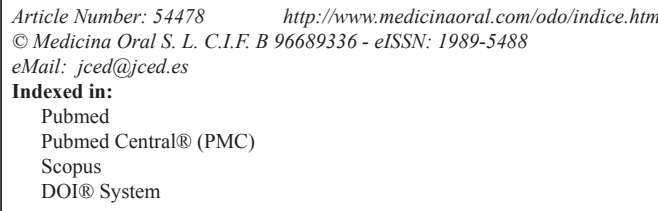

\begin{abstract}
Background: Titanium is a less studied trace element in dental enamel. Literature relates an increased Titanium concentration with a decreased enamel crystal domain size, which in turn is related to a higher color value. The aim of our study was to analyze the effect of tooth bleaching agents on its concentration in dental enamel by means of confocal Raman spectroscopy.

Material and Methods: Human teeth were randomly distributed in six experimental groups $(\mathrm{n}=10)$ and submitted to different bleaching protocols according to the manufacturer's instructions. Confocal Raman spectroscopy was carried out in order to identify and quantify the presence of titanium dioxide molecules in enamel prior to and during whitening. Statistical analysis included repeated measures analysis of variance $(p \leq 0.05)$ and Bonferroni pairwise comparisons.

Results: Titanium dioxide concentration was negatively affected by the longer bleaching protocols (at-home bleaching gels). All in-office whitening products increased significantly the studied molecule $(p \leq 0,05)$.

Conclusions: All dental specimens depicted the presence of titanium dioxide as a trace element in dental enamel. Bleaching gels that have to be applied at higher concentrations but for shorter periods of time increase the concentration of titanium dioxide, whilst at-home whitening gels used for longer periods of time despite the lower concentration caused a loss in titanium.
\end{abstract}

Key words: Bleaching, whitening, hydrogen peroxide, carbamide peroxide, Raman spectroscopy, titanium dioxide. 


\section{Introduction}

Dental enamel consists primarily of hydroxyapatite (HA), which is composed of calcium, phosphate and hydroxyl ions. However, there are other substances present in very small amounts called "trace materials", which might be related to enamel physical properties. Among these substances, titanium can be found, which is a less studied trace element related to enamel color and hardness.

To confirm the presence of these materials, since the early 1930s, Drea obtained spectra of 18 dried teeth by means of exciting the trace elements with a direct current method, and found out that there are several elements present in human enamel and dentin. Among those can be mentioned: $\mathrm{Al}, \mathrm{Fe}, \mathrm{Ba}, \mathrm{Cu}, \mathrm{F}, \mathrm{Pb}, \mathrm{Li}, \mathrm{Mn}, \mathrm{K}$, $\mathrm{Si}, \mathrm{Ag}, \mathrm{Sr}, \mathrm{V}, \mathrm{Zn}$ and Ti. (1) According to some authors, the content of trace materials is related to the subject's dietary and life style characteristics (2), other researches who have studied enamel trace materials in animals believe they are related to geographic location, and that these are key elements for complex archeological and biology studies, among others (3).

Some investigators relate the content of trace elements with the presence of caries. Riyat and Sharma observed that carious teeth presented a slight decrease in elements such as $\mathrm{Sr}, \mathrm{Ca}, \mathrm{Mg}, \mathrm{P}, \mathrm{Be}, \mathrm{V}, \mathrm{Ni}, \mathrm{Zn}, \mathrm{Nb}, \mathrm{Ag}, \mathrm{Cd}, \mathrm{Sb}, \mathrm{Ba}$, $\mathrm{La}, \mathrm{W}, \mathrm{Pb}, \mathrm{Bi}$ and Ti (4). Their results are complementary with another study whose authors suggest that $\mathrm{Zn}$ is present in a population less prone to caries formation (5). The results of these studies are not conclusive and often contradictory, which shows that further research is necessary in order to understand the role of trace elements in the caries formation.

Other investigations relate trace elements with the crystallographic characteristics of HA, whose size might be eventually related to its optical and physical properties.
Eimar and others found that a smaller size of the enamel crystals was the major predictor for higher tooth lightness (6), they also found that the size of the carbonated apatite crystals along the c-axis is inversely proportional to its hardness (7). Literature reports that an increased Ti concentration in hydroxylapatite results in decreased enamel crystal domain size as well as decreased cell lattice parameters (8).

Some extrinsic factors might influence element concentration in dental enamel. Hydrogen peroxide, used for dental bleaching, affects phosphate and carbonate concentration (9-15), however the effect on Ti, among other trace elements, remains unknown. Since Ti is related to a smaller size of hydroxyapatite crystals and thus increased tooth lightness, it was the aim of our study to analyze the effect of tooth bleaching agents on Ti concentration and its variation among the treatment weeks. Therefore, this paper reports on our progress so far with the study of the trace material titanium by modifying whitening agents and shows how this approach can be applied for studying other trace materials.

\section{Material and Methods}

The present research protocol was approved by the Research Commission of the Dental Faculty at the University of Costa Rica.

Research methodology was described elsewhere (15). Briefly, sixty sound human teeth, extracted for periodontal and/or orthodontic reasons were randomly divided into six experimental groups according to the type of whitening gel (Table 1). Raman spectra readings were performed always on the same spot, previously marked with two lines on the buccal surface of each tooth. This specific area was also the place where the bleaching agent was applied.

Measurements were carried out by means of a confocal

Table 1: List of treatment groups and materials used.

\begin{tabular}{|c|c|c|c|c|c|}
\hline Group & $\mathbf{n}$ & Product & Composition & Batch \# & Instructions for use \\
\hline 1 & 10 & Day White ${ }^{\circledR}$ & Hydrogen peroxide $9,5 \%$ & 14150012 & 30 minutes twice a day / 28 days \\
\hline 2 & 10 & Day White ${ }^{\circledR}$ & Hydrogen peroxide $14 \%$ & 14043020 & \\
\hline 3 & 10 & Day White ${ }^{\circledR}$ & Carbamide peroxide $38 \%$ & 14150024 & \\
\hline 4 & 10 & $\begin{array}{c}\text { Zoom! } \\
\text { Whitespeed }\end{array}$ & Hydrogen peroxide $25 \%$ & 15112019 & $\begin{array}{c}\text { Group 4: } 15 \text { minutes/ photo-activated } \\
\text { (3 times) }\end{array}$ \\
\hline 5 & 10 & PolaOffice & Hydrogen peroxide $35 \%$ & 151633 & $\begin{array}{l}\text { Group 5: } 8 \text { minutes/photo-activated } \\
\text { (3 times) }\end{array}$ \\
\hline 6 & 10 & PolaOffice & Hydrogen peroxide $35 \%$ & 151633 & $\begin{array}{c}\text { Group 6: } 8 \text { minutes/not photoactivated } \\
\text { (3 times) }\end{array}$ \\
\hline
\end{tabular}


Raman spectrometer (Model Alpha300 R from the company WiTec, Ulm, Germany), fitted with a $100 \mathrm{~mW} \mathrm{He} /$ $\mathrm{Ne}$ laser (785 nm wavelength). Laser diameter was circa $50 \mu \mathrm{m}$. All spectra were measured with an integration time of $0,5 \mathrm{~s}$ and one hundred acquisitions. The above in order to enhance the signal-to-noise ratio of the relevant peaks. A typical Raman spectra of dental enamel would have a peak at $139-154 \mathrm{~cm}^{-1}$ correspondent to symmetric titanium dioxide stretching vibration states in all Raman spectra of the dental enamel specimens.

After the base-line readings, bleaching gels were applied and readings were made again at the second and fourth treatment weeks for groups 1-3. Readings for groups 4-6 were made after the first and second bleaching. For the in-office bleaching groups, two consecutive applications were made at the first session, and one application was performed at the second session a week after. Spectra were improved by subtracting the ambient noise from the laser spectra. We also analyzed the intensity of the background in pursuance of the loss of organic content in the teeth after the whitening agent, nevertheless the signal-to-noise ratio was not high enough in order to be able to draw conclusions.

PeakFit ${ }^{\circledR}$ (Systat Software Inc.) software was employed to calculate the area under the curve corresponding to the Ti peak. All data was normalized with the Rayleigh peaks prior to the statistical analysis in order to compensate for the possible variations in the ambient conditions. Repeated measures analysis of variance (ANOVA) and post hoc Bonferroni test was applied to observe differences among the treatment weeks in each experimental group.

\section{Results}

Table 2 shows the multivariate analysis for titanium molecules, which change significantly along the treatment weeks, and behave also significantly different among the treatment groups. However, when the experimental groups are analyzed by the type of whitening procedure, at-home versus in-office bleaching, it can be seen that there is no difference among the experimental groups, but rather only among the treatment weeks.

Figure 1 shows that at-home bleaching agents (groups 1-3) produce a decrease in the titanium molecule. For groups 2 and 3 this decrease was significant at the second and fourth week of treatment, when compared to the respective control week (Table 3).

In-office bleaching agents (groups 4-6) on the other hand, showed a significant increase in Ti (Table 3 ) in relation to the control week.

Table 2: Multivariate test for experimental group and treatment week.

\begin{tabular}{|l|c|c|c|}
\hline Variables & \multicolumn{3}{|c|}{ Significance* } \\
\hline & Groups 1, 2,3,4, 5, 6 & Groups 1,2,3 & Groups 4,5,6 \\
\hline Treatment week & 0.042 & 0,000 & 0,000 \\
\hline Treatment week*Group & 0,000 & 0,187 & 0,204 \\
\hline$p \leq 0,05$ & \multicolumn{4}{|l|}{} \\
\hline
\end{tabular}
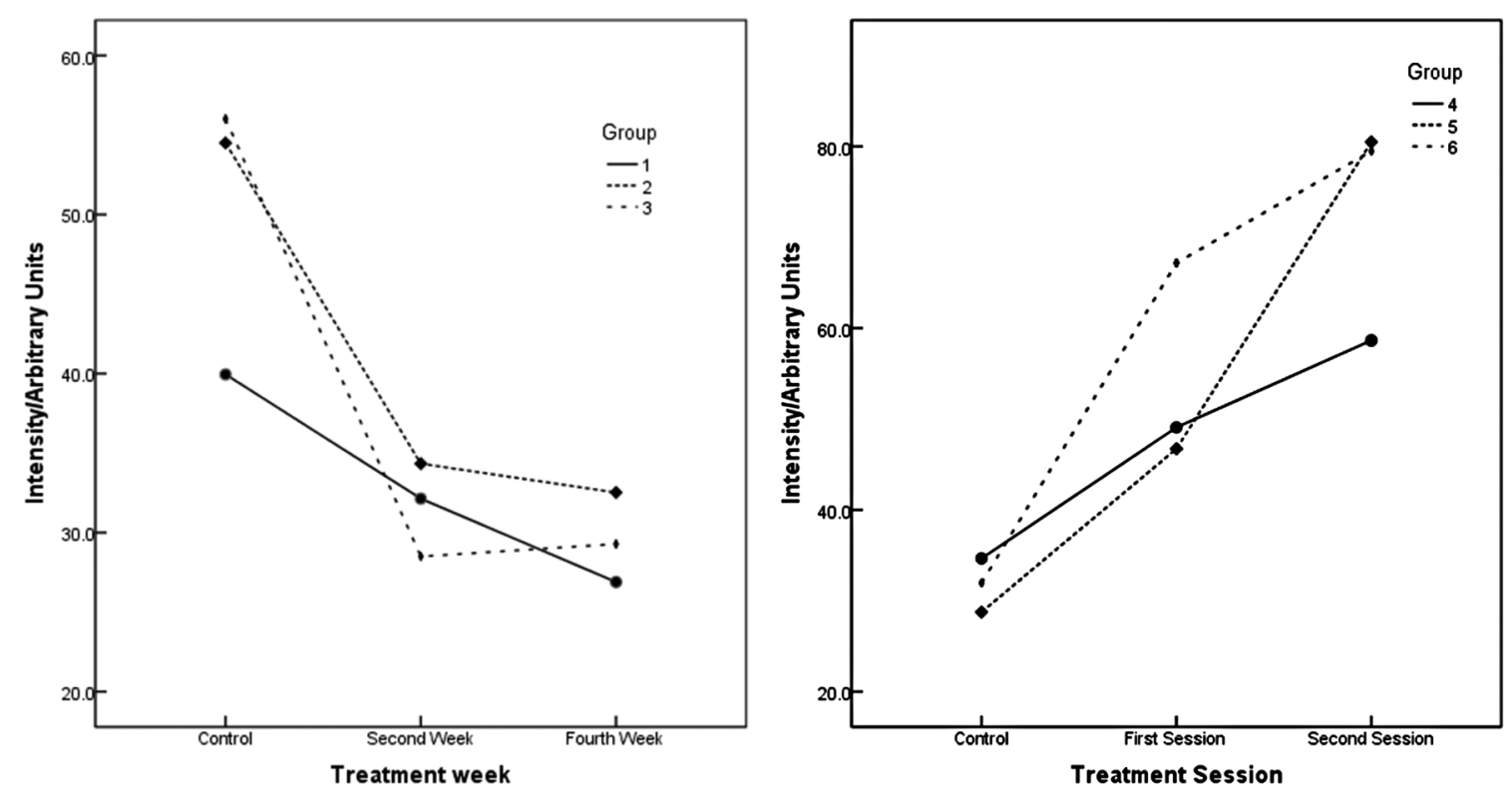

Fig. 1: Variation of the Titanium during the treatment weeks. 
Table 3: Significant Bonferroni pairwise comparisons.

\begin{tabular}{|c|c|c|c|c|c|}
\hline \multirow[t]{2}{*}{ Group } & \multirow[t]{2}{*}{ Week } & \multirow[t]{2}{*}{ Week } & \multirow[t]{2}{*}{ Sig. ${ }^{a}$} & \multicolumn{2}{|c|}{$\begin{array}{l}\text { 95\% Confidence } \\
\text { Interval }\end{array}$} \\
\hline & & & & Lower & Upper \\
\hline \multirow[t]{3}{*}{1} & \multirow[t]{2}{*}{ Control } & Week 2 & 0,85 & $-12,28$ & 27,90 \\
\hline & & Week 4 & 0,32 & $-8,23$ & 34,34 \\
\hline & Week 2 & Week 4 & 0,99 & $-9,76$ & 20,25 \\
\hline \multirow[t]{3}{*}{2} & \multirow[t]{2}{*}{ Control } & Week 2 & 0,00 & 11,06 & 29,28 \\
\hline & & Week 4 & 0,00 & 8,90 & 35,07 \\
\hline & Week 2 & Week 4 & 1,00 & $-9,29$ & 12,92 \\
\hline \multirow[t]{3}{*}{3} & \multirow[t]{2}{*}{ Control } & Week 2 & 0,00 & 11,87 & 43,17 \\
\hline & & Week 4 & 0,05 & $-0,44$ & 53,91 \\
\hline & Week 2 & Week 4 & 1,00 & $-21,63$ & 20,05 \\
\hline \multirow[t]{3}{*}{4} & \multirow[t]{2}{*}{ Control } & Week 2 & 0,39 & $-39,86$ & 11,03 \\
\hline & & Week 4 & 0,03 & $-45,81$ & $-2,17$ \\
\hline & Week 2 & Week 4 & 0,72 & $-31,91$ & 12,76 \\
\hline \multirow[t]{3}{*}{5} & \multirow[t]{2}{*}{ Control } & Week 2 & 0,11 & $-39,79$ & 3,84 \\
\hline & & Week 4 & 0,00 & $-86,35$ & $-17,13$ \\
\hline & Week 2 & Week 4 & 0,07 & $-70,51$ & 2,99 \\
\hline \multirow[t]{3}{*}{6} & \multirow[t]{2}{*}{ Control } & Week 2 & 0,02 & $-63,53$ & $-6,88$ \\
\hline & & Week 4 & 0,04 & $-92,74$ & $-2,29$ \\
\hline & Week 2 & Week 4 & 1,00 & $-49,87$ & 25,25 \\
\hline
\end{tabular}

\section{Discussion}

Titanium dioxide is a little studied trace element in dental enamel. However, it is a broadly employed additive in food and pharmaceuticals. Its primary use is as a pigment, because of its brightness and high refractive index (16). A group of researchers analyzed different commercially available products and reported that the foods with the highest content of $\mathrm{TiO}_{2}$ were candies, powered drink mixes and chewing gums with a hard shell, on the other hand personal care products like toothpastes and sunscreens contained up to $1 \%-10 \%$ titanium by weight (16). Few of these products list $\mathrm{Ti}$ on the packaging and the mean size of the particles is about 100 to $300 \mathrm{~nm}$.

$\mathrm{TiO}_{2}$ is also incorporated in tooth pastes (17) due to its effect on enamel and cementum solubility. Although Ti solutions at high concentrations have a strong acidity and might damage the tooth surface, low concentration solutions combined with highly concentrated fluorides decrease the solubility of cementum. Titanium binds to the organic molecules of the dental tissue and in this way fluorides are trapped in the matrix, making the surface less soluble and allowing a slower release of fluorides over time (18). Cementum is more beneficiated by this effect, since it has a greater organic component than enamel.

Due to the broad employment of $\mathrm{TiO}_{2}$, this molecule is easily dispersed into water and air, which can explain its presence as a trace element in dental tissues. During controlled experiments, our study corroborated the pre- sence of this molecule by means of Raman spectroscopy in all dental specimens analyzed. Furthermore, we could observe that in-office whitening products (hydrogen peroxide at higher concentration applied in fewer sessions) produced a different effect on titanium dioxide in comparison to at-home bleaching gels.

Lower concentration whitening agents employed for a prolonged period of time (at-home bleaching) caused a decrease in titanium concentration. This is in agreement with other publications, and might be because to the degradation of the enamel superficial layer, as well as the oxidation in the organic matter after a prolonged exposure to these chemical substances $(9,13)$. It must be noted that the higher decrease was observed at the second week of treatment, and that it stabilized towards the fourth week.

In-office bleaching protocols caused the inverse effect, since $\mathrm{TiO}_{2}$ increased its concentration during both application sessions, regardless of the activation with light. According to the literature, an increase in $\mathrm{Ti}$ is related to a decrease in the size of hydroxyapatite crystals (19), which in turn is related to a higher value $(6,8)$. This mechanism might be one of the reasons why in-office whitening produces a higher value already from the first application since, according to Eimar, smaller enamel crystals cause a higher light scattering. This improvement must be seen with caution, since smaller crystal size is correlated to lower enamel hardness (7). 


\section{Conclusions}

The analysis of all dental specimens revealed the presence of titanium dioxide.

The effect of dental bleaching seems to be dependent on the peroxide concentration and on the period of application.

Bleaching gels at higher concentrations and employed on fewer sessions seem to increase the titanium dioxide concentration, whereas gels at lower concentrations employed for a prolonged period of time cause a decrease in the molecule.

\section{References}

1. Curzon MJ, Losee FL. Dental caries and trace element composition of whole human enamel: Eastern United States. J Am Dent Assoc. 1977;94:1146-50.

2. Jaouen $\mathrm{K}$, Herrscher E, Balter V. Copper and zinc isotope ratios in human bone and enamel. Am J Phys Anthropol. 2017;162:491-500.

3. Qamar Z, Haji Abdul Rahim ZB, Chew HP, Fatima T. Influence of trace elements on dental enamel properties: A review. J Pak Med Assoc. 2017;67:116-20.

4. Riyat M, Sharma DC. Analysis of 35 inorganic elements in teeth in relation to caries formation. Biol Trace Elem Res. 2009;129:126-9.

5. Fatima T, Haji Abdul Rahim ZB, Lin CW, Qamar Z. Zinc: A precious trace element for oral health care? J Pak Med Assoc. 2016;66:1019-23. 6. Eimar H, Marelli B, Nazhat SN, Abi Nader S, Amin WM, Torres $\mathrm{J}$, et al. The role of enamel crystallography on tooth shade. J Dent. 2011;39:e3-e10.

7. Eimar H, Ghadimi E, Marelli B, Vali H, Nazhat SN, Amin WM, et al. Regulation of enamel hardness by its crystallographic dimensions. Acta Biomater. 2012;8:3400-10.

8. Ghadimi E, Eimar H, Marelli B, Nazhat SN, Asgharian M, Vali H, et al. Trace elements can influence the physical properties of tooth enamel. Springerplus. 2013;2:499.

9. Jiang $\mathrm{T}$, Ma X, Wang Y, Tong H, Shen X, Hu Y, et al. Investigation of the effects of $30 \%$ hydrogen peroxide on human tooth enamel by Raman scattering and laser-induced fluorescence. J Biomed Opt. 2008;13:014019.

10. Santini A, Pulham CR, Rajab A, Ibbetson R. The effect of a $10 \%$ carbamide peroxide bleaching agent on the phosphate concentration of tooth enamel assessed by Raman spectroscopy. Dent Traumatol. 2008;24:220-3.

11. Venkatesan SM, Narayan GS, Ramachandran AK, Indira R. The effect of two bleaching agents on the phosphate concentration of the enamel evaluated by Raman spectroscopy: An ex vivo study. Contemp Clin Dent. 2012;3:172-6.

12. Götz H, Duschner H, White DJ, Klukowska MA. Effects of elevated hydrogen peroxide 'strip' bleaching on surface and subsurface enamel including subsurface histomorphology, micro-chemical composition and fluorescence changes. J Dent. 2007;35:457-66.

13. Sun L, Liang S, Sa Y, Wang Z, Ma X, Jiang T, et al. Surface alteration of human tooth enamel subjected to acidic and neutral $30 \%$ hydrogen peroxide. J Dent. 2011;39:686-92.

14. Sa Y, Wang Z, Ma X, Lei C, Liang S, Sun L, et al. Investigation of three home-applied bleaching agents on enamel structure and mechanical properties: an in situ study. J Biomed Opt. 2012;17:035002.

15. Vargas-Koudriavtsev T, Herrera-Sancho OA. Effect of tooth-bleaching on the carbonate concentration in dental enamel by Raman spectroscopy. J Clin Exp Dent. 2017;9:e101-6.

16. Weir A, Westerhoff P, Fabricius L, Hristovski K, von Goetz N. Titanium dioxide nanoparticles in food and personal care products. Environ Sci Technol. 2012;46:2242-50.

17. Afonso RL, Pessan JP, Igreja BB, Cantagallo CF, Danelon M, Delbem AC. In situ protocol for the determination of dose-response effect of low-fluoride dentifrices on enamel remineralization. J Appl Oral Sci. $2013 ; 21: 525-32$.
18. Koray M, Oner-Iyidogan Y, Soyman M, Gürdöl F. The effects of fluorides and/or trace elements on the solubilities of enamel and cementum. J Trace Elem Med Biol. 1996;10:255-9.

19. Huang J, Best SM, Bonfield W, Buckland T. Development and characterization of titanium-containing hydroxyapatite for medical applications. Acta Biomater. 2010;6:241-9.

Acknowledgments

This Project was financed with the Special Research Promoting Fund of the University of Costa Rica.

\section{Conflict of Interest}

The authors of the present study deny any financial and personal relationships with other people or organizations that could inappropriately influence (bias) their work. 